\title{
A IMPORTÂNCIA DA ANÁLISE DOS COMPONENTES ECONÔMICOS PARA EVITAR QUE AS EMPRESAS ENTREM EM RECUPERAÇÃO JUDICIAL
}

Juliana Medeiros, Márcia Satie Takahashi Ferreira, Simone Nemézio da Costa Siqueira, Stephanie Caroline Silva Cavalcante, Pedro Teófilo de Sá

Universidade do Oeste Paulista - UNOESTE, Curso de Ciências Contábeis, Presidente Prudente, SP. E-mail: julianamed.medeiros@gmail.com

\begin{abstract}
RESUMO
A auditoria tem um papel fundamental para assegurar a análise dos registros e proporcionar credibilidade nas tomadas de decisões. Os instrumentos usados pelo auditor contribuirão para a gestão, em busca de um caminho para o sucesso da atividade empresarial. Este artigo traz uma resposta para seguinte problemática: Quais os componentes do cenário econômico que podem ser analisados pelos auditores para encontrar os fatores que levarão uma empresa a recuperação judicial? O objetivo deste estudo é identificar os componentes do cenário econômico que podem ser usados pelos auditores, para se evitar a recuperação judicial, na busca de resultados mais eficientes, que manterão estabelecimento empresarial em funcionamento, sanando as dificuldades financeiras e estruturais.
\end{abstract}

Palavras-chave: Auditoria. Recuperação Judicial. Economia. Empresas. Mercado.

\section{THE IMPORTANCE OF ECONOMIC ANALYSIS OF COMPONENTS TO AVOID ENTERING THE FIRMS IN JUDICIAL RECOVERY}

\begin{abstract}
The audit plays a key role in ensuring analysis of records and provide credibility in decisionmaking. The instruments used by the auditor will contribute to the management, searching for a path to successful business activity. This article provides an answer to the following issues: What are the components of the economic scenario that can be analyzed by the auditors to find the factors that will lead the company to bankruptcy? The objective of this study is to identify the components of the economic scenario that can be used by auditors to avoid bankruptcy in the search for more efficient results, that will keep business establishment in operation, solving the financial and structural difficulties.
\end{abstract}

Keywords : Audit. Judicial recovery. Economy. Companies. Marketplace. 


\section{INTRODUÇÃO E OBJETIVO}

Nota-se, há anos, no Brasil, que é grande o número de empresas micro, pequeno, médio ou grande porte, que encerram suas atividades, devido a inúmeros motivos, dentre eles se destacam a má gestão e o papel do profissional contábil na empresa.

Com a finalidade de minimizar os danos causados na economia, decorrentes destes fechamentos, o governo vem realizando diversas medidas, dentre elas, a que tem atraído a atenção é a recuperação judicial de empresas, conforme consta na lei de falências e recuperação de empresas, a lei 11.101/2005.

A referida lei foi criada com o intuito de evitar o fechamento de organizações, através da apresentação de um plano de recuperação, e reestruturação econômica, que pode ser tanto judicial quanto extrajudicial.

Então, diante dos problemas enfrentados pelas empresas, diante do cenário econômico nacional, questiona-se: quais são os componentes do cenário econômico que podem ser analisados pelos profissionais da área contábil, os auditores, para encontrar os fatores que levam uma empresa a recuperação judicial? Assim, o objetivo deste estudo é identificar os componentes do cenário econômico que podem ser utilizados pelos auditores, na busca pelos fatores evitam uma empresa chegar a recuperação judicial.

Diante disso, o presente estudo é importante porque busca discutir tal questão, beneficiando os empresários e profissionais contábeis, contribuindo com o processo reflexivo e de tomada de decisão na organização.

\section{METODOLOGIA}

Este artigo científico foi realizado por uma abordagem qualitativa, tendo como instrumento de coleta de dados uma pesquisa bibliográfica, através de livros, revistas, artigos científicos e sites especializados.

\section{RESULTADOS}

Para a empresa poder se manter no mercado, a fim de evitar eventual processo de recuperação, ela precisa estar atenta às informações disponibilizadas pelo controle interno, que deve obedecer a legalidade dos lançamentos. Mas não deverá desprezar os componentes da economia, como a escassez, a oferta, e a demanda, pois esses fatores darão suporte para a empresa, o produto, o tipo de consumidor e a concorrência de mercado. 
Estas informações subsidiarão os relatórios gerenciais produzidos pelo profissional contábil, o que facilita conhecer o mercado e a pretensão da empresa, na busca do equilíbrio entre oferta e demanda voltado para o melhor preço. Esses fatores auxiliam na estratégia gerencial e subsidiam o processo de tomada de decisão.

\section{DISCUSSÃO}

A recuperação judicial é um novo procedimento previsto na nova lei de falências de 2005, que visa recuperar empresas que estão em dificuldades financeiras. Esse novo instituto substituiu a antiga concordata. Ambas apresentam a mesma finalidade, evitar a falência das empresas.

De acordo com Coelho (2011, p. 414), a recuperação judicial é uma forma de reorganizar a vida da empresa, o que beneficia credores, empregados e a economia. Portanto, a recuperação judicial acontece quando a organização não consegue quitar as dívidas com os seus credores, e toma uma medida judicial para evitar a falência. É um momento de reestruturação e reorganização financeira que favorece a empresa, já que mantém a produção ou circulação de bens e serviços.

"[...] a lei exige a concordância tanto do devedor como dos outros credores aderentes para que um desses últimos possa se liberar do previsto no plano." (COELHO, 2011, p. 438). Observa-se então, que é necessário que os credores concordem com o plano de recuperação. Mas, para que isso ocorra, será analisado se a empresa atende ao princípio da viabilidade, e se ela reúne condições de se manter no mercado.

Após a concordância, o plano será homologado pelo poder judiciário. A empresa deverá seguir e cumprir as metas e o cronograma de pagamentos, sob a pena de ter a falência decretada.

É preciso que os empresários detenham mais conhecimentos, mesmo que genéricos, sobre as possibilidades e efeitos trazidos pela nova lei, para recuperação de empresas. 0 artigo 48 da Lei no 11.101, de 9 de fevereiro de 2005, elenca os requisitos e condições para o requerimento de recuperação judicial.

Art. 48. Poderá requerer recuperação judicial o devedor que, no momento do pedido, exerça regularmente suas atividades há mais de 2 (dois) anos e que atenda aos seguintes requisitos, cumulativamente:I - não ser falido e, se o foi, estejam declaradas extintas, por sentença transitada em julgado, as responsabilidades daí decorrentes;II - não ter, há menos de 5 (cinco) anos, obtido concessão de recuperação judicial;ill - não ter, há menos de 8 (oito) anos, obtido concessão de recuperação judicial com base no plano especial de que trata a Seção V deste Capítulo;IV - não ter sido condenado ou não ter, como administrador ou sócio controlador, pessoa condenada por qualquer dos crimes previstos nesta Lei. 
Vale destacar que, quem já entrou em processo de recuperação judicial há menos de cinco anos não poderá solicitar a recuperação novamente, como também microempresas ou empresas de pequeno porte, que entraram em recuperação judicial com base no plano especial. Neste caso não poderá ser inferior a oito anos.

Portanto, nota-se a importância de um profissional da área contábil, um cantador ou auditor, para instruir o processo de recuperação judicial. O papel analítico e de orientação é de extrema importância, pois servirão de base para a tomada de decisão na empresa e a escolha pela decisão da escolha ou não do processo de recuperação.

Atualmente, o auditor e o contador desempenham papel de extrema responsabilidade, fundamental dentro da organização. São eles, em conjunto, ou separadamente, que darão segurança e total transparência nas informações para um processo de recuperação. Então, é indispensável abordar acerca da necessidade do controle interno, diante do cenário econômico, para que o contador ou auditor possam instrumentalizar as empresas em suas atividades.

O controle interno é procedimento de facilitação da gestão, ou ainda, um meio de intensa fiscalização, que auxilia na expansão das atividades. Por isso, necessita de profissionais para controlar e garantir a lucratividade da empresa acompanhando a rotina de trabalho, verificando improbidades administrativas. Nesse sentido, encontra-se o teor da resolução $n^{\circ} 321 / 72$, do Conselho Federal de Contabilidade, dispõe o seguinte:

O controle interno compreende o plano de organização e o conjunto coordenado dos métodos e medidas, adotados pela empresa, para proteger seu patrimônio, verificar a exatidão e o grau de confiança de seus dados contábeis, bem como promover a eficiência operacional.

Diante desse conceito, observa-se que o controle interno tem como foco proteger o patrimônio de prejuízos decorrentes de fraudes e erros intencionais ou não, além de assegurar a integridade dos registros contábeis, que subsidiarão os responsáveis pela tomada de decisão, e ainda, promover a eficiência e eficácia operacionais da organização, dentro de normas estabelecidas.

Desta forma o controle interno contribui significativamente para a garantia do atingimento dos objetivos da empresa.

Todas as áreas e setores das entidades, constituindo-se como um plano de organização balanceado quanto às responsabilidades e autoridades nos diversos níveis da organização, que se utiliza de um conjunto coordenado de tarefas e atividades efetuadas por pessoas em todos os níveis organizacionais, 
visando fornecer uma garantia razoável, não absoluta, da realização dos objetivos, metas e políticas da entidade. (ATTIE, 2011, p. 190).

Nota-se que o controle interno é o conjunto de procedimentos, métodos ou rotinas que objetivam salvaguardar os ativos, confeccionar dados contábeis confiáveis, e auxiliar a administração, a conduzir os negócios da empresa, de maneira ordenada.

As abordagens funcionais da gestão da informação, como contabilidade, finanças, informática etc., refletem sobre a perspectiva conjunta de melhorar a qualidade da geração e distribuição de informação, aos diferentes tipos de usuários.

A quantidade de dados e informações a que as organizações estão expostas diariamente demanda um gerenciamento eficaz, sendo esse aspecto parte integrante do processo decisório dos dirigentes e gestores dentro das organizações. (BEUREN 2000 apud STROEHER)

Fica claro então, que, para que as organizações obtenham sucesso na gestão de recursos e da atividade comercial, elas precisam da assistência do profissional contábil, que as auxiliarão no processo de tomada de decisão, o que favorece a manutenção da solidez no mercado, fato que certamente previne um processo de recuperação.

Após entender o procedimento do controle interno, é preciso analisar a escassez como componentes do cenário econômico, que pode ser utilizada por um auditor, a fim de identificar a falta ou excesso de recursos na atividade empresarial. Segundo Sandroni (1999, p. 211), "Em termos econômicos, a escassez surge do pressuposto de que as necessidades humanas são infinitas, ao passo que os bens ou os meios de satisfazê-las são sempre finitos".

Com isso, pode-se produzir o suficientemente um bem econômico, mas não ser capaz de produzir todos os bens para atender a todas as necessidades existentes. Os recursos básicos para produzir os bens econômicos são: o trabalho, a terra e o capital. Daí surge à escassez, onde a ciência econômica busca uma forma de reduzi-la de maneira eficiente através das formas de produção, tecnologia e distribuição dos bens, ou seja, ela mostra como economizar recursos.

De acordo com os estudos realizados por Besanko e Braeutigam (2004, p. 2), “A escassez significa que as escolhas dos bens e serviços a serem produzidos e, portanto, as necessidades humanas, estão sujeitas a restrições".

As empresas devem decidir se irão produzir bens de consumo ou de capital, quais métodos que serão utilizados para a produção, dependendo dos recursos disponíveis, e quem será beneficiado com a distribuição destes produtos ou serviços. Isso se dará através de um estudo na região onde há a pretensão de comercializar, verificando se existem recursos necessários, qual o 
tamanho da concorrência e qual a necessidade dos clientes. Este procedimento dará segurança ao possível investimento.

O segundo componente a ser utilizado por um auditor são a oferta e demanda. O intuito é o de identificar a relação entre o preço e o produto ou serviço oferecido para o consumo. Para Motella (2012, p. 2) "A microeconomia é, justamente, a parte da Economia que estuda a determinação dos preços dos bens e serviços. Essa determinação virá do confronto das forças de oferta e demanda".

É preciso abordar separadamente essas forças. A primeira a ser tratada é a demanda, que nada mais é do que o resultado da vontade e da necessidade do consumidor. A empresa tem que entender qual é o tipo de consumidor que será alcançado, uma vez que, mercados que envolvem consumidores movidos pela vontade têm maior volatilidade, ao contrário daqueles movidos pela necessidade.

Outra questão relevante a respeito da demanda é a elasticidade. Com produtos elásticos, a demanda vai variar de acordo com o valor do bem. Já em produtos inelásticos, acontece o contrário, a demanda é sempre constante, independente do preço do bem, uma vez que são produtos necessários.

Entendidos esses dois pontos, e sabendo-se que a demanda é a quantidade de algum produto ou serviço, que os consumidores desejam adquirir em um determinado período. Pode-se entender a oferta, que é definida como a quantidade de bens e serviços que os produtores (empresas) desejam produzir e oferecer ao mercado (VASCONCELLOS, 2011).

Se a oferta é a quantidade desses bens e serviços que as empresas desejam oferecer ao mercado, é certo afirmar que, quanto maior for o valor do produto ofertado, maior vai ser a quantidade de quem produz e quer vender. Walter (2010, p. 37) afirma que "À medida que o preço sobe, a quantidade demandada diminui, ao passo que a quantidade que os vendedores desejam vender aumenta.".

Por isso, tem que haver o equilíbrio de mercado entre ofertantes e demandantes. Esse equilíbrio acontece quando há a interação entre oferta e demanda. Nesse momento, o preço deixa de mudar e a demanda e oferta igualam-se, ou seja, compradores compram as quantidades que eles desejam como também vendedores vendem a quantidade que desejam, e isso é chamado de preço de equilíbrio (Walter, 2010).

Esses aspectos sobre a oferta e a demanda, são o mínimo o que as empresas precisam saber para acertar no tipo de produto a oferece, o tipo de consumidor que querem atender, de modo que saibam como agir com as constantes mudanças que ocorrem no mercado. 
O próximo componente que pode ser utilizado por um auditor é a concorrência, que serve para determinar a produção e a estruturação no mercado, assim como seus recursos. A concorrência é subdividida em: concorrência perfeita, monopólio e concorrência imperfeita. A estrutura do mercado, a qual a empresa se insere, é um elemento crucial para determinar a oferta e o ambiente competitivo existente.

De acordo com Vasconcellos (2011, p. 183):

Por estrutura de mercado queremos denotar o ambiente competitivo existente, que vai desde um mercado perfeitamente competitivo, passando por um cenário de oligopólio até um mercado monopolizado, conforme existam respectivamente muitas, poucas ou apena uma firma atuando no mercado de um bem.

Os atores envolvidos nestes cenários são os que ofertam (vendedores) e os que demandam (compradores).

Em concorrência perfeita, tanto os vendedores como os compradores estão em um grande número no mercado, porém, são pequenos diante da situação em que nenhum deles tem condição, isoladamente, de afetar o preço do produto transacionado (homogêneo). Também são classificados como tomadores de preço, já que decidem quanto produzir ou comprar a partir do preço dado pelo mercado.

[...] uma indústria de competição perfeita surge, basicamente, por duas razões. Primeira se a escala mínima de eficiência de um único produtor é pequena em relação à demanda pelo bem ou serviço [...] Segunda razão, uma indústria de competição perfeita aparece quando cada firma pertencente a esse setor é vista pelo consumidor como uma entidade que produz um bem ou serviço homogêneo [...] (CABRAL, 2008, p.180)

Observa-se a predominância do menor valor, pois os consumidores se importam com o preço do bem e o serviço comprado.

“Monopólio é uma estrutura de mercado em que um único vendedor de um produto sem nenhum substituto próximo atende a todo o mercado" (FRANK, 2013, p. 372).

Então, há monopólio quando apenas uma empresa produz determinada mercadoria sem concorrentes próximos, é ainda caracterizado por obter lucro econômico puro, mesmo que em longo prazo, onde também é necessário que outras empresas não entrem neste mercado para continuar sendo monopolistas.

E por fim, tem-se a concorrência imperfeita quando a possibilidade da concorrência e as firmas individuais afetarem o preço por meio de decisões isoladas. Segundo Vasconcellos (2011, p. 
221) "Este modelo procura encontrar um meio-termo mais realista entre os extremos de competição perfeita e monopólio, reunindo elementos dessas duas estruturas de mercado."

Deve-se, portanto, determinar a produção, a estrutura em cada mercado e se os recursos são eficientes, resultando na relação entre produção e preço e em conseqüência valorizando os recursos escassos.

\section{CONCLUSÃO}

O objetivo deste estudo é identificar os componentes do cenário econômico que podem ser utilizados pelos auditores, na busca pelos fatores evitam uma empresa chegar a recuperação judicial. Com a pesquisa procurou-se abordar o processo de recuperação judicial das empresas, e assim identificar os componentes do cenário econômico a serem utilizados por profissionais, e entender esses fatores.

Portanto conclui-se que o uso de um plano organizacional, através dos controles internos, juntamente com os componentes da economia, a escassez, servem para analisar as necessidades humanas, o que serve de vetor para a produção de bens, da oferta e da demanda. Esses fatores servem para as empresas analisarem os aspectos dos produtos oferecidos, o tipo de consumidor que querem atender, e a concorrência. Tudo isso serve de instrumento ao auditor ou contador para avaliar se a concorrência é perfeita, monopolista ou imperfeita, o que permitirá uma analise do posicionamento das empresas no mercado, assim como avaliar se o produto ou serviço oferecido está de acordo com a pretensão do negócio.

Certamente com esse conjunto de instrumentos, para apoio da análise estratégica gerencial, a empresa poderá se manter no mercado sem a necessidade de se utilizar da recuperação judicial.

\section{REFERÊNCIAS}

ATTIE, W. Auditoria: Conceitos e Aplicações. 6. Ed. São Paulo: Atlas, 2011.

BEUREN, I.M. Gerenciamento da informação: um recurso estratégico no processo de gestão empresarial. 2 ed. São Paulo: Atlas, 2000.

BESANKO, D. BRAEUTIGAM, R. Microeconomia: Uma abordagem completa. 1 o ed. Rio de Janeiro: LTC, 2004.

CABRAL, A. S. YONEYAMA, T. Microeconomia: uma visão integrada para empreendedores. 1 ed. São Paulo: Saraiva, 2008.

COELHO, F. U. Manual de direito comercial. 23. ed. São Paulo: Saraiva, 2011. 
Conselho. Disponível<http://www2.cfc.org.br/sisweb/sre/detalhes_sre.aspx?codigo=1972/000321 > Acesso em: 02 de maio de 2015.

DORIA, D. Curso de Direito Comercial. 13a ed. rev. Atual. São Paulo: Saraiva, 2008.

FRANK, R. H. Microeconomia e comportamento. 8 ed. Porto Alegre: AMGH, 2013.

GONÇALVES, M. G. V. P. R.; GONÇALVES, V. E. R. Direito Comercial: direito de empresa e sociedades empresárias. 3.ed. São Paulo: Saraiva, 2010.

MONTELLA, Micro e macroeconomia: uma abordagem conceitual e prática. 2 ed. São Paulo: Atlas, 2012.

Presidência da República. Casa Civil. Subchefia para assuntos jurídicos. Apresenta art. 48 da Lei 11.101. Disponível em <http://www.planalto.gov.br/ccivil_03/_ato20042006/2005/lei/l11101.htm> Acesso em 25 de abril de 2015.

RAMALHO, Z. L. A. Empresa na ordem econômica: princípios e função social. Curitiba: Juruá, 2009.

REQUIÃO, R. Curso de Direito Comercial, vol. 1; 32ª edição; São Paulo: Saraiva, 2013.

STROEHER A. M., FREITAS H. Revista de Administração eletrônica. O uso das informações contábeis na tomada de decisão em pequenas empresas. Disponível em <http://www.rausp.usp.br/Revista_eletronica/v1n1/artigos/v1n1a7.pdf> Acesso em: 27 de abril de 2015.

SANDRONI, Paulo. Novíssimo Dicionário de Economia. 1 ed. São Paulo: Best Seller, 1999.

VASCONCELLOS, M. A. S. de. Economia Micro e Macro. 5 ed. São Paulo: Atlas, 2011.

Walter, Microeconomia: Teoria e Aplicações. 2 ed. São Paulo: Saraiva, 2010. 